\title{
GSM-GPS-RF based Alert Generating Device
}

\author{
Aditya Singh Chauhan \\ Resource Person \\ Chhattisgarh Vigyan Sabha \\ Raipur, India
}

\begin{abstract}
The world today is definitely progressing but with that there has been a massive rise in crime rate. Sexual abuse is one of the most pressing issues. Need of the hour is safety and security of women and children. The GSM-GPRS Based Alert Generating Device which would hereby be called as 'Akshara' is an electronic device, which on invoking, is capable of alerting nearest police stations, preset emergency contacts and community volunteers of the victim's whereabouts and basic personal information.
\end{abstract}

\section{General Terms}

Police Control Room (PCR), Global Positioning System (GPS), Radio Frequency (RF), Unique Identity of Device (UID), Uniform Resource Locator (URL)

\section{Keywords}

AKSHARA, Wearables, Safety Device, Crime Prevention,

\section{INTRODUCTION}

According to National Crime Records Bureau (India), 337,992 cases were reported towards crimes against women, which include 36,735 Rapes in the year 2014, counting to be about 101 rapes every day. In addition to that, 89,423 crimes

were reported against children in the year 2014. The world today is definitely progressing but with that there has been a massive rise in crime rate (http://www.indiaspend.com/coverstory/crimes-against-women-reported-every-two-minutes84240). Sexual abuse is one of the most pressing issues. Need of the hour is safety and security of women and children.

\begin{tabular}{|c|c|c|c|c|c|c|c|}
\hline \multicolumn{8}{|c|}{ Crimes Against Women (2005-2010) } \\
\hline & & & & & & & $\%$ variation \\
\hline \multirow[t]{2}{*}{ Crime } & & \multicolumn{2}{|r|}{ Year } & & & & in 2010 \\
\hline & 2005 & 2006 & 2007 & 2008 & 2009 & 2010 & over 2009 \\
\hline Rape & 18,359 & 19,348 & 20,737 & 21,467 & 21,397 & 22,172 & 3.6 \\
\hline Incest Rape & N.A & N.A & N.A & 309 & 404 & 288 & -10.3 \\
\hline Kidnapping \& Abduction & 15,750 & 17,414 & 20,416 & 22,939 & 25,741 & 29,795 & 15.7 \\
\hline Dowry Death & 6,787 & 7,618 & 8,093 & 8,172 & 8,383 & 8,391 & 0.1 \\
\hline Torture & 58,319 & 63,128 & 75,930 & 75,930 & 89,546 & 94,041 & 5 \\
\hline Molestation & 34,175 & 36,617 & 38,734 & 40,413 & 38,711 & 40,613 & 4.9 \\
\hline Sexual Harassment & 9,984 & 9,966 & 10,950 & 12,214 & 11,009 & 9,961 & -9.5 \\
\hline Importation of Girls & 149 & 67 & 61 & 67 & 48 & 36 & -25 \\
\hline Sati Prevention Act & 1 & 0 & 0 & 1 & 0 & 0 & - \\
\hline Immoral Traffic & 5,908 & 4,541 & 3,568 & 2,659 & 2,474 & 2,499 & 1 \\
\hline Indecent Representation of & 2,917 & 1,562 & 1,200 & 1,025 & 845 & 895 & 5.9 \\
\hline Women & & एँचा & chntrid & ta.cors & & & \\
\hline Dowry Prohibition & 3,204 &,- 504 & $-5,023$ & 5,555 & $-5,650$ & $-5,182$ & -8.3 \\
\hline Total & $1,55,553$ & $1,64,765$ & $1,85,312$ & $1,95,856$ & $2,03,804$ & $2,13,585$ & 4.8 \\
\hline Source: National Cithe Re & cords Bur & Eau, New & Dellhi- & & & & \\
\hline
\end{tabular}

Fig. 1. Crimes against Women (2005-2010) Statistics

(Source - National Crime Records Bureau, India)

The GSM-GPS-RF Based Alert Generating Device which would henceforth be called as 'Akshara' is an electronic device, which on invoking, is capable of alerting three nearest police stations, preset emergency contacts and community volunteers of your location. The server at the back end generates automatic voice calls and generate notifications with the interpreted location of the victim to the three nearest police stations, preset emergency contacts and community volunteers with the primary information of the victim and simultaneously sends Mobile application based notifications to the identified police stations comprising of victim's location plotted on the Google Map with real time tracking and personal information of the victim viz. Photograph, Contact Numbers, Address, Guardian Contact numbers etc for followup process. The gadget once invoked shall start sending the location to the police stations and emergency contacts every 3 seconds enabling real-time tracking. In addition to that, the device also provides parental tracking system through which parents and guardians of users can get to know of their wards location in real time through SMS in textual address format, and upon suspicion police alert can be generated at their end too through SMS.

\section{METHODOLOGY}

The proposed device comprises of RF Transmitter/Receiver, GSM-GPRS Module, GPS Module, 16-Pin Microcontroller viz. Arduino and $2000 \mathrm{mAh}$ Li-Ion Battery. Victim, in case of distress could invoke the gadget by pressing a button embedded in the transmitter part of the gadget. The receiver part of the gadget keeps looping for positive high signal from the transmitter. The transmitter transmits the high signal after having the button pressed. Receiving the high signal, the RF receiver passes the same high signal to the microcontroller. The microcontroller which is set to check for the high signal from the RF Receiver every $100 \mathrm{~ms}$ requests the GPS Module for the data. Having received the position related data from GPS Module, micro-controller drafts a text consisting of an URL integrating the encrypted UID of the device and GPS data within. Post the text drafting, the microcontroller transmits the drafted text accompanied by a cellular node address to the GSM Module that would in turn sends the text as SMS. This SMS is directed towards a server that does the back end processing.

At the server end,

Step 1: The system initially decrypts and validates the request and passes on to the processing module. The processing module parses the request into UID and geographic coordinates.

Step 2: Secondly, the system hits on the database to fetch data of the Police Stations and community volunteers' present in a respective region identified by the victim's geographical coordinates.

Step 3: Distance of the police stations from the victim's position is calculated and sorted in an associative array. At the same time, another thread fetches victim's data along with its pre-set emergency contacts.

Step 4: A textual address of the victim's geographical location is fetched using Google's address interpreting API and temporarily stored. 
Step 5: With the identification of the 3 nearest police stations and regional community volunteers, automated voice calls are generated alerting the authorities of the incident and Victim's primary information which includes its name, interpreted current location and its distance from the respective police stations and volunteers.

Step 6: Simultaneous to Step 5, the system also generates notifications on the dedicated Mobile Application to the identified Police Stations, PCRs and volunteers. These notifications would comprise of Victim's location plotted on Google Map, Victim's photograph and its basic personal information viz. Address, Guardian Contact numbers etc.

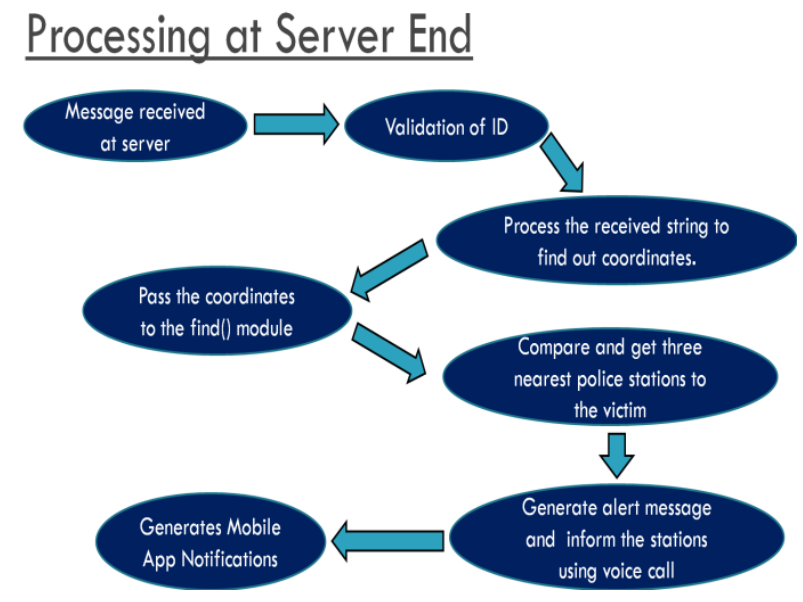

Fig. 2: Processing at Server End

In addition to the normal gadget invoking process, the proposed GSM-GPS-RF Based Alert Generating Device gets triggered through a Parental Tracking Module (PTM). Through PTM, the parents/guardian of the user can track their ward's location by requesting the server using a predefined code and server in return would respond with a SMS consisting of user's location in a textual format. In case of suspicion, parents/guardian can trigger the whole Police/Volunteer alerting process by replying a pre-defined code to the SMS received.

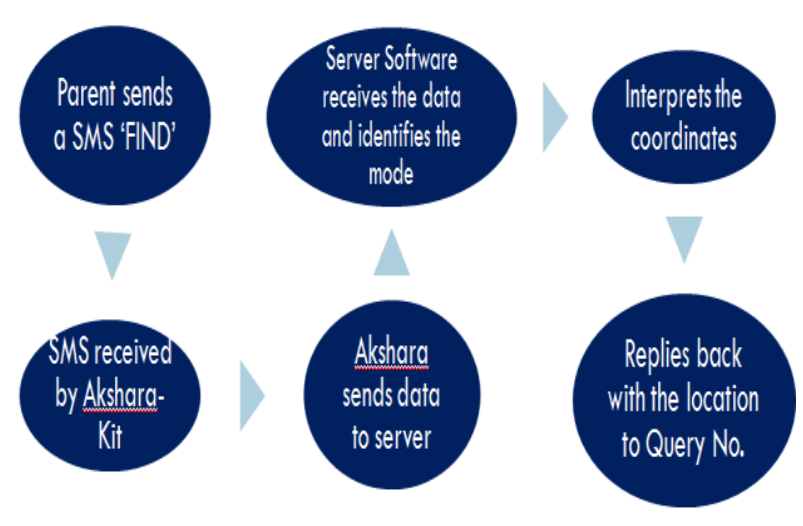

Fig. 3: Parental Tracking Process

\section{CONCLUSION}

The device is capable of generating alerts with an error of +-5 meters. It takes 30 seconds to compute the desirable nodes (in present case Police Stations, Emergency Contacts and Community Volunteers) and generates voice calls and notifications simultaneously. This device could bring about a drastic change in the field of wearable technology for personal safety. Costing to be around 1500 INR and yet could be a gadget of most utility in the present scenario, at the same time viable to all sections of society. The device is independent of Mobile Phone and Internet, thus making it accessible in areas with relevant issues. It works on an error of +-5 meters and performs computation in considerably short time. It is extremely easy to use and is so small that it could be manufactured in any shape desired. They system is also planned to have a geographical safety analysis which would provide alerts in real time to users based on their location. We are also working towards making the device independent of cellular networks. This device is the need of the hour ; Not only for Women but for Children who might or might not be given cell phones, For Elderly ones, to generate alerts in case of emergency, for riders in case of any on road emergency.

\section{ACKNOWLEDGMENTS}

We express our sincere gratitude towards Mr. Asad Siddique (Researcher) to guide us towards the idea and to validate our concepts. We are thankful to Mr. C.S. Robinson (Asso. Prof, Dept. of Applied Physics, BIT-Durg) for making our idea technically feasible, for suggesting a lot of new ways as to how our aim could be achieved. We are also thankful to Vishwas Meshram (Vice President, CGVS, Raipur) for his constant support and guidance.

\section{REFERENCES}

[1] Crimes Against Women in India, National Crime Records Bureau, New Delhi, India http://ncrb.nic.in/StatPublications/CII/CII2014/chapters/ Chapter205.pdf

[2] Christopher de Charms, Mobile Security Technology, https://patentscope.wipo.int/search /en/detail.jsf?doc $\mathrm{Id}=\mathrm{WO} 2014182638$

[3] Adnan I. Yaqzan, Issam W. Damaj, and Rached N. Zantout(July24, 2008), 'GPS-Based Vehicle Tracking System - On - Chip', Proceedings of the world Congress on Engineering Vol. I WCE

[4] A. Stone, J. Brigg: \| SMS and Interactivity - Some Results from the Field, and its Implications on Effective Uses of Mobile Technologies in Education" : IEEE Computer Society, Craig Smith Issue Date: August 2002

[5] Michael Martin Saigh, Kevin Richard Arndt, Andrew Victor Saigh, Personal safety mobile notification system, https://www.google.com/patents/US8624727

[6] Akhil SEHGAL, Ashbum, VA (US) https://docs.google.com/viewer?url=patentimages.storag e.googleapis.com/pdfs/US20150065082.pdf

[7] Bradly Michael Zotti, David D. Dixon, Charles Richardson Groves Personal safety application for mobile device and method( US20120329420 A1 ) 